\title{
TEORES DE NUTRIENTES FOLIARES NO MARACUJAZEIRO-AMARELO ASSOCIADOS À ESTAÇÃO FENOLÓGICA, ADUBAÇÃo POTÁSSICA E LÂMINAS DE IRRIGAÇÃOO ${ }^{1}$
}

\author{
ALMY JUNIOR CORDEIRO DE CARVALHO², DONIVALDO PEDRO MARTINS 3 , PEDRO HENRIQUE \\ MONNERAT $^{4}$, SALASSIER BERNARDO ${ }^{4}$ e JOSÉ ACCÁCIO DA SILVA 5
}

\begin{abstract}
RESUMO - Conduziu-se um experimento em Campos dos Goytacazes-RJ, para avaliar o efeito da adubação potássica, de lâminas de irrigação e de épocas do ano nos teores de N, P, K, Ca, Mg, S, Zn, Fe, Cu, B, Cl, Mn e Na no maracujazeiro-amarelo (Passiflora edulis f. flavicarpa). Foram testadas, num Argissolo Amarelo distrófico, quatro doses de potássio (76; 307; $531 \mathrm{e} 764 \mathrm{~g} \mathrm{planta}^{-1}$ ano $^{-1} \mathrm{de} \mathrm{K}$ ), utilizando o cloreto de potássio, sob seis lâminas de irrigação $(0 ; 25 ; 50 ; 75 ; 100$ e $125 \%$ da ETo - Evapotranspiração de referência), num esquema fatorial $4 \times 6$. Os teores de nutrientes, na matéria seca foliar, relacionados com a máxima produtividade de frutos $\left(43,5 \mathrm{tha}^{-1}\right)$, variaram, nas diferentes épocas do ano, de 34,7 a 49,8 $\mathrm{g} \mathrm{kg}^{-1} \mathrm{de} \mathrm{N}, 2,31$ a $3,43 \mathrm{~g} \mathrm{~kg}^{-1} \mathrm{de} \mathrm{P}, 23,5$ a 35,5 $\mathrm{g} \mathrm{kg}^{-1} \mathrm{de} \mathrm{K}, 10,6$ a $15,1 \mathrm{~g} \mathrm{~kg}^{-1} \mathrm{de} \mathrm{Ca}$, 2,13 a 3,62 $\mathrm{g} \mathrm{kg}^{-1} \mathrm{de} \mathrm{Mg}, 3,19$ a 4,33 $\mathrm{g} \mathrm{kg}^{-1}$ de S, 16,9 a 28,9 $\mathrm{g} \mathrm{kg}^{-1}$ de Cl, 77 a $135 \mathrm{mg} \mathrm{kg}^{-1}$ de Fe, 50,1 a 91,4 mg kg-1 de Mn, 26,1 a 37,6 mg $\mathrm{kg}^{-1}$ de Zn, 4,53 a 95,4 mg kg-1 de Cu, 22,8 a 54,5 mg kg-1 de B e de 0,96 a 2,31 $\mathrm{g} \mathrm{kg}^{-1} \mathrm{de} \mathrm{Na}^{-} \mathrm{O}$ adubo potássico elevou os teores de $\mathrm{K}$ e $\mathrm{Cl}$ e reduziu os de $\mathrm{Mg}, \mathrm{Mn}, \mathrm{Zn}$ e Na nas folhas do maracujazeiro. A irrigação afetou os teores de $\mathrm{N}, \mathrm{Cl}$ e Na e não influenciou nos teores foliares dos demais nutrientes avaliados.
\end{abstract}

Termos de indexação: fertilização, maracujá, potássio, nutrientes foliares, Passiflora edulis

\section{NUTRIENTS CONTENTS IN THE LEAF DRY MATTER ASSOCIATED WITH SEASONAL PHENOLOGY, POTASSIUM FERTILIZATION AND IRRIGATION DEPTHS IN YELLOW PASSIONFRUIT}

\begin{abstract}
A field experiment was carried out, in Rio de Janeiro State, Brazil, to evaluate the effect of potassium fertilization and irrigation treatments, on the nutrients $\mathrm{N}, \mathrm{P}, \mathrm{K}, \mathrm{Ca}, \mathrm{Mg}, \mathrm{S}, \mathrm{Zn}, \mathrm{Fe}, \mathrm{Cu}, \mathrm{B}, \mathrm{Cl}, \mathrm{Mn}$ and $\mathrm{Na}$ in leaf contents in yellow passion fruit (Passiflora edulis f. flavicarpa). Were tested, on a Rhodic Paleudult soils, four rates of potassium (76, 307, 531 and $764 \mathrm{~g} \mathrm{plant}^{-1}$ year ${ }^{-1}$ of K), utilized potassium chloride, and six irrigation levels $(0,25,50,75,100$ and $125 \%$ of ETo - reference crop evapotranspiration for grass), in a factorial scheme $4 \times 6$. The nutrients leaf contents, at maximum fruit yield $\left(41.3 \mathrm{tha}^{-1}\right)$, ranged from 34.7 to $49.8 \mathrm{~g} \mathrm{~kg}^{-1}$ of organic N, 1.51 to $1.80 \mathrm{~g} \mathrm{~kg}^{-1}$ of $\mathrm{NO}_{3}^{-}, 2.31$ to $3.43 \mathrm{~g} \mathrm{~kg}^{-1}$ of P, 23.5 to $35.5 \mathrm{~g} \mathrm{~kg}^{-1}$ of $\mathrm{K}, 10.6$ to $15.1 \mathrm{~g} \mathrm{~kg}^{-1}$ of Ca, 2.13 to $3.62 \mathrm{~g} \mathrm{~kg}^{-1} \mathrm{of} \mathrm{Mg}^{-3.19}$ to $4.33 \mathrm{~g} \mathrm{~kg}^{-}$ ${ }^{1}$ of S; from 0.96 to $2.31 \mathrm{~g} \mathrm{~kg}^{-1}$ of Na, 16.9 to $28.9 \mathrm{~g} \mathrm{~kg}^{-1}$ of Cl, 77 to $135 \mathrm{mg} \mathrm{kg}^{-1}$ of Fe, 50.1 to $91.4 \mathrm{mg} \mathrm{kg}^{-1}$ of Mn, 26.1 to $37.6 \mathrm{mg} \mathrm{kg}^{-1}$ of $\mathrm{Zn}, 4.53$ to $95.4 \mathrm{mg} \mathrm{kg}^{-1}$ of Cu, 22.8 to $54.5 \mathrm{mg} \mathrm{kg}^{-1}$ of B and from $0.96 \mathrm{a} 2.31 \mathrm{~g} \mathrm{~kg}^{-1}$ of Na. Potassium fertilization increased leaf contents of the $\mathrm{K}$ and $\mathrm{Cl}$ and decreased $\mathrm{Mg}, \mathrm{Mn}, \mathrm{Zn}$ and $\mathrm{Na}$. Irrigation influenced leaf contents of the $\mathrm{N}, \mathrm{Cl}$ and $\mathrm{Na}$ and did not affect the leaf contents of the others nutrients.
\end{abstract}

Index terms: fertilization, Passiflora edulis, potassium, leaf nutrient status

\section{INTRODUÇÃO}

O maracujazeiro tem apresentado, no Brasil, altas taxas de crescimento na área plantada nos últimos anos, passando de 28.259 ha em 1989 para 44.462 ha em 1996 (Agrianual, 2000), sendo uma das fruteiras com maior potencial de exploração para o Brasil, tanto para o mercado interno, quanto para o, ainda pouco explorado, mercado externo. No Estado do Rio de Janeiro, a área cultivada com esta fruteira vem mantendo-se estável nos últimos anos, estando em torno de 1.600 ha, mesmo com as excelentes condições de clima e solo e com o enorme potencial de mercado existente, além da instalação, nos últimos anos, de algumas fábricas que processam o fruto.

A produtividade do maracujazeiro-amarelo no Brasil situa-se numa ampla faixa, variando de 5 a $70 \mathrm{t} \mathrm{ha}^{-1}$ ano $^{-1}$, sendo que a média nacional, em torno de 9,2 $\mathrm{t} \mathrm{ha}^{-1}$ ano $^{-1} \mathrm{em} 1996$ (Agrianual, 2000), é muito baixa quando se observa o potencial produtivo da cultura. A inadequada ou não-utilização de práticas culturais recomendadas, entre elas a adubação e a irrigação, têm sido responsáveis pela obtenção de valores tão baixos.

Os níveis adequados de nutrientes encontrados pela análise foliar ainda não foram estabelecidos para o maracujazeiro em suas fases fenológicas. Porém, alguns autores admitem faixas adequadas para macro e micronutrientes, nas condições em que foram determinadas, observando-se grande variação nas informações apresentadas. Kliemann et al. (1986) explicam que essas divergências podem ser ocasionadas por várias razões, como diferenças na época de amostragem, na parte amostrada,

1 Trabalho $n^{\circ}$ 115/2000. Recebido: 29/06/2000. Aceito para publicação: 06/06/2001.

2 Eng. Agr., D.Sc., Prof ${ }^{0}$ Associado, UENF/CCTA/LFIT, Campos, RJ, CEP 28015-620. E-mail: almy@uenf.br

3 Eng. Agr., D.Sc., IICA/INCRA, Brasília, DF, CEP 70873-020. E-mail: doni@incra.gov.br

4 Eng. Agr., Ph.D, Prof ${ }^{\circ}$ Titular, UENF/CCTA, Campos, RJ, CEP 28015-620. E-mail: monnerat@uenf.br

5 Eng. Químico, Técnico de Nível Superior, UENF/CCTA, Campos, RJ, CEP 28015-620 
nas variedades, no manejo, etc.

Segundo Menzel et al. (1993), os padrões foliares desenvolvidos preliminarmente para o maracujazeiro não podem ser extrapolados diretamente para pomares comerciais, porque os procedimentos de amostragem não foram bem definidos. Muitos autores não consideraram, em seus experimentos, o efeito da estação de crescimento, a idade da folha, o estádio de frutificação e a fase fenológica da planta.

Menzel et al. (1993) observaram que as concentrações foliares de N, P e K apresentaram grandes flutuações durante o ano; entretanto, apenas as mudanças na concentração do $\mathrm{K}$ apresentaram diferenças significativas. Ocorreu um declínio na concentração de N, P e K após o período de máximo desenvolvimento vegetativo e durante o período de pegamento do fruto, refletindo a mobilização dos nutrientes para o desenvolvimento dos ramos, flores e frutos.

O potássio $\left(\mathrm{K}^{+}\right)$é um nutriente com diversos papéis no metabolismo vegetal. Atua como ativador enzimático de processos responsáveis pela síntese e degradação de compostos orgânicos e participam no processo de abertura e fechamento das células estomatais, síntese de proteínas, osmorregulação, extensão celular e balanço entre cátions e ânions (Marschner, 1995; Malavolta et al., 1989). É requerido em larga quantidade pelas culturas, sendo o cátion mais abundante nos vegetais, afetando o rendimento e a qualidade dos produtos colhidos (Daliparthy et al., 1994).

No maracujazeiro, a deficiência de $\mathrm{K}^{+}$provoca clorose seguida de necrose nas margens das folhas, inicialmente das mais velhas, diminuição no crescimento dos ramos, perda de folhas e baixo pegamento de flores. O início da floração é atrasado, ocorre queda prematura, mumificação ou diminuição significativa no tamanho dos frutos e queda no teor de sólidos solúveis do suco (Malavolta, 1994).

Considerando a extração total, o $\mathrm{N}$ é o elemento absorvido em maior quantidade durante o desenvolvimento do maracujazeiro, seguido pelo $\mathrm{K}^{+}$. Entretanto, por ocasião da colheita, o $\mathrm{K}^{+}$é o mais extraído. Isto se deve ao fato de a concentração de $\mathrm{K}^{+}$na casca dos frutos ser, aproximadamente, o dobro daquela observada para o N (De Paula et al., 1974, citados por Kliemann et al., 1986; Haag et al., 1973). Considerando isto, pode-se afirmar que o $\mathrm{K}^{+}$é o nutriente mais exportado dos pomares, visto que as partes colhidas são os frutos.

As práticas de manejo aplicadas aos solos brasileiros, em geral carentes em minerais potássicos facilmente intemperizáveis, concorrem para que o balanço de $\mathrm{K}^{+}$no sistema solo-planta seja, em muitas situações, negativo. Freqüentemente, as perdas por erosão, lixiviação e exportação desse nutriente pelas culturas são maiores que as adições promovidas pelas adubações potássicas, o que acaba por comprometer o processo produtivo.

A interação entre o $\mathrm{K}^{+}$e outros cátions ocorre tanto na parte aérea quanto no solo. Adubações potássicas podem levar à diminuição dos níveis foliares de Mg (Reis Jr., 1995; Rhue et al., 1986) e de Ca (Reis Jr., 1995; Locascio et al., 1992), pois potássio, cálcio e magnésio competem por sítios de absorção pela planta. O potássio reduz a concentração de $\mathrm{Mg}$ na parte aérea através da redução da sua translocação das raízes para a parte aérea (Ohno e Grunes, 1985, citados por Reis Jr., 1995). A alteração dessas concentrações de nutrientes pode trazer problemas ao crescimento vegetal, à morfologia da planta e afetar sua produção.

O excesso de potássio no solo pode inibir a absorção do magnésio. Claassen e Wilcox (1974) constataram que o aumento da concentração de potássio na solução do solo resultou em redução da absorção de magnésio pelas raízes de milho. Em solução nutritiva, o efeito inibitório do potássio sobre a absorção do magnésio em azevém, cevada, milho e beterraba cessou quando a concentração de potássio ao redor das raízes atingiu valores inferiores a $2 \mathrm{mmol}_{\mathrm{c}} \mathrm{L}^{-1}$, dobrando a taxa de absorção do magnésio (Seggewiss e Jungk, 1988, citados por Fonseca e Meurer, 1997). Fonseca e Meurer (1997) concluíram, para o milho, que devido à alta demanda, a taxa de absorção de $\mathrm{K}^{+}$pelas raízes é normalmente muito mais alta do que a do $\mathrm{Mg}^{++}$. A interface solo-raiz, dessa forma, é muito mais rapidamente exaurida de potássio do que de magnésio e, assim, à medida que a concentração do $\mathrm{K}^{+}$decresce, o influxo do $\mathrm{Mg}^{++}$aumenta.

Analisando mensalmente, durante um ano, folhas recém-maduras de goiabeira, Shikhamany et al. (1986) observaram grandes flutuações no conteúdo de NPK. Malavolta et al. (1989) ressaltam o fato de o clima, o solo, a época de amostragem e a variedade poderem alterar os teores foliares dos nutrientes.

$\mathrm{O}$ bom aproveitamento dos fertilizantes pela planta depende muito de adequada disponibilidade de água. A absorção de alguns nutrientes parece ser marcadamente prejudicada pela falta de água. Entretanto, o excesso de água pode elevar em demasia as perdas causadas pela lixiviação de nutrientes tais como $\mathrm{N}\left(\mathrm{NO}_{3}^{-}\right)$e K $\mathrm{K}^{+}$(Raij, 1991; Malavolta et al., 1989).

Os objetivos do presente trabalho foram avaliar os efeitos da adubação potássica e de diferentes lâminas de irrigação, sobre os teores, na matéria seca foliar, de $\mathrm{N}$ orgânico (Norg), $\mathrm{NO}_{3}^{-} \mathrm{P}, \mathrm{K}, \mathrm{Ca}, \mathrm{Mg}, \mathrm{S}, \mathrm{Zn}, \mathrm{Fe}, \mathrm{Cu}, \mathrm{B}, \mathrm{Cl}, \mathrm{Mn}$ e Na, em diferentes épocas do desenvolvimento do maracujazeiro-amarelo cultivado no Norte do Estado do RJ.

\section{MATERIAL E MÉTODOS}

O experimento foi instalado no município de Campos dos Goytacazes-RJ $\left(\right.$ Latitude $=21^{\circ} 19^{\prime} 23^{\prime \prime}$; Longitude $=41^{\circ} 10^{\prime}$ 40 " W; Altitude $=14 \mathrm{~m}$ ), em um Argissolo Amarelo distrófico, desenvolvido a partir de sedimentos terciários, com camada superficial arenosa, horizonte B textural e relevo suave ondulado, que representa bem as condições edafoclimáticas das áreas onde se cultiva o maracujazeiro-amarelo na região Norte Fluminense. As umidades do solo na capacidade de campo e no ponto de murcha permanente, até a profundidade de $40 \mathrm{~cm}$, foram estimadas, através da curva característica de retenção de água no solo, em $13 \%$ e $6,5 \%$ em volume, respectivamente.

A análise do solo, por ocasião do plantio, apresentava as seguintes características nas camadas de 0 a 20 e 20 a $40 \mathrm{~cm}$, respectivamente: $\mathrm{pH}$ em $\mathrm{H}_{2} \mathrm{O}(1: 2,5)=5,7$ e 5,4; $\mathrm{P}=16 \mathrm{e} 3 \mathrm{mg} \mathrm{kg}^{-1} ; \mathrm{Ca}=18 \mathrm{e} 12 \mathrm{mmol}_{\mathrm{c}} \mathrm{kg}^{-1} ; \mathrm{Mg}=10$ e 8 mmol $_{\mathrm{c}} \mathrm{kg}$ ${ }^{1} ; \mathrm{K}=1,15$ e $0,4 \mathrm{mmol}_{\mathrm{c}} \mathrm{kg}^{-1} ; \mathrm{Na}=1,7 \mathrm{e} 0,4 \mathrm{mmol}_{\mathrm{c}} \mathrm{kg}^{-1} ; \mathrm{Al}=2 \mathrm{e}$ $2 \mathrm{mmol}_{\mathrm{c}} \mathrm{kg}^{-1} ; \mathrm{H}+\mathrm{Al}=9,8 \mathrm{e} 19,7 \mathrm{mmol}_{\mathrm{c}} \mathrm{kg}^{-1} ;$ Carbono $=7 \mathrm{e} 4 \mathrm{~g} \mathrm{~kg}^{-}$ ${ }^{1} ; \mathrm{CE}=1,4 \mathrm{e} 1,35 \mathrm{dS} \mathrm{m}^{-1}$; Areia fina $=240$ e $220 \mathrm{~g} \mathrm{~kg}^{-1}$; Areia grossa $=440$ e $410 \mathrm{~g} \mathrm{~kg}^{-1} ;$ Silte $=60$ e $25 \mathrm{~g} \mathrm{~kg}^{-1} ;$ Argila $=260$ e 345 $\mathrm{g} \mathrm{kg}^{-1}$; Densidade aparente $=1,78 \mathrm{~g} \mathrm{~cm}^{-3}$.

A água utilizada na irrigação apresentava, em fev./96 
e ago./97, respectivamente, as seguintes características químicas: $\mathrm{pH}=6$ e 4,$5 ; \mathrm{CE}=0,75$ e $0,66 \mathrm{dS} \mathrm{m}^{-1}$; Cloreto $=236$ e $167 \mathrm{mg} \mathrm{L}^{-1}$; $\mathrm{Ca}=20$ e $5 \mathrm{mg} \mathrm{L}^{-1} ; \mathrm{Mg}=25$ e $15 \mathrm{mg} \mathrm{L}^{-1} ; \mathrm{K}=4$ e $4,5 \mathrm{mg} \mathrm{L}^{-1} ; \mathrm{Na}=$ 45 e $80 \mathrm{mg} \mathrm{L}^{-1}$ sendo, portanto, classificada como C2S1 (Bernardo, 1995), indicando que pode ser usada para irrigação de plantas com razoável tolerância a sais, sempre que o solo permitir um grau moderado de lixiviação, e com pequena possibilidade de elevar o Na trocável no solo a níveis perigosos.

O delineamento experimental adotado foi o de blocos casualizados, em esquema fatorial $4 \times 6$, com três repetições. Os tratamentos utilizados corresponderam a 4 doses de potássio $\mathrm{K}\left(76,307,531\right.$ e 764 g planta $^{-1}$ ano $\left.^{-1} \mathrm{de} \mathrm{K}\right)$, na forma de cloreto de potássio, sob 6 lâminas de irrigação - L $(0 ; 25 ; 50 ; 75 ; 100$ e $125 \%$ da evapotranspiração de referência - ETo), que corresponderam a lâminas totais de água (irrigação + precipitação efetiva entre mar./96 e jun./97) de 826; 1.048; 1.199; 1.319; 1.476 e 1.714 mm de água, respectivamente. As parcelas foram constituídas por três fileiras com 24 plantas, em espaçamento de $3 \times 2$ metros, sendo úteis as 6 plantas centrais $\left(36 \mathrm{~m}^{2}\right)$.

O plantio foi realizado em fevereiro de 1996, e as plantas foram conduzidas no sistema de espaldeira vertical, com um fio de arame, a 1,8 m de altura em relação ao nível do solo. Foram realizados os tratos culturais que se fizeram necessários, tais como controle de plantas daninhas e tratamentos fitossanitários. Utilizaram-se, preventivamente, pulverizações com fungicidas à base de oxicloreto de cobre para controle de algumas doenças, principalmente a bacteriose (Xanthomonas campestri pv. passiflorae) e a verrugose (Cladosporium herbarum Link).

Todos os tratamentos receberam uma dose constante de $35 \mathrm{~g}$ de $\mathrm{P}$, na forma de superfosfato simples, $25 \mathrm{~g}$ de $\mathrm{K}$, na forma de cloreto de potássio, e $50 \mathrm{~g}$ de FTE-BR12, incorporados na cova 30 dias antes do plantio. Foram aplicados 10 e 16,6 g planta $^{-1}$ de N e K, respectivamente, aos 30; 60 e 90 dias após o plantio. Os adubos, em cobertura, foram aplicados numa faixa de, aproximadamente, 30 a $40 \mathrm{~cm}$ distante do colo da planta, espalhados numa faixa de 20 a $30 \mathrm{~cm}$ de largura ao redor da planta. As doses de $\mathrm{K}$, correspondentes aos tratamentos, foram divididas em 10 parcelas iguais durante o ano, entre maio/96 e maio/97, omitindo-se as aplicações nos meses de jul./96 e jan./97. Por ocasião da aplicação do adubo potássico, aplicou-se uma dose constante de $20 \mathrm{~g}_{\text {planta }}{ }^{-1}$ de N, totalizando $200 \mathrm{~g} \mathrm{planta}^{-1}$ ano $^{-1}$.

Nos tratamentos com irrigação, a água foi aplicada, inicialmente, através de um sistema de gotejamento por tubogotejador denominado "Queen Gil". Em set./96, trocou-se o sistema de irrigação por outro com gotejadores autocompensantes do tipo "Katif", com vazão de $3,75 \mathrm{~L} \mathrm{~h}^{-1}$. O controle do volume aplicado por parcela foi feito com hidrômetros instalados nas linhas de distribuição do sistema. Utilizou-se um turno de rega de 2 dias. Um tanque classe A, com o qual foi estimada a ETo, e um pluviômetro foram instalados na área, o que permitiu quantificar o volume de água a ser aplicado diariamente na cultura, sendo que o referido volume foi determinado conforme descrito a seguir: $\left.1^{\circ}\right) \mathrm{CTA}=$ capacidade total de água no solo, $\mathrm{mm}$;

$\left.2^{\circ}\right) \mathrm{CRA}=$ capacidade real de água no solo, $\mathrm{mm}(\mathrm{CRA}=\mathrm{CTA} \times \mathrm{f})$, sendo $\mathrm{f}=$ fator de disponibilidade igual a 0,5 ;

$\left.3^{\circ}\right) \mathrm{ETo}=$ evapotranspiração potencial de referência, em mm dia ${ }^{1}(\mathrm{ETo}=\mathrm{EV} \times \mathrm{Kt})$, sendo EV = evaporação do tanque classe A e Kt $=$ coeficiente do tanque sempre igual a 0,70 ;

$\left.4^{\circ}\right) \mathrm{ETpc}=$ evapotranspiração potencial da cultura, em mm dia ${ }^{-1}$
$(\mathrm{ETpc}=\mathrm{ETo} \times \mathrm{Kc})$, sendo o $\mathrm{Kc}=$ coeficiente de cultura igual a 0,4 do plantio até 60 dias após, igual a 0,6 de 60 até 120 dias após o plantio e 0,75 após este período;

$\left.5^{\circ}\right)$ LAA = lâmina atual de água no solo, $\mathrm{mm}(\mathrm{LAA}=\mathrm{CTA}-$ ETrc), adotando-se LAA = CTA para o $1^{\circ}$ dia do balanço;

$\left.6^{\circ}\right) \mathrm{ETrc}=$ evapotranspiração real da cultura, $\mathrm{mm} \mathrm{dia}^{-1}(\mathrm{ETrc}=$ ETpc x Ks);

$\left.7^{\circ}\right) \mathrm{Ks}=$ coeficiente de umidade do solo $(\mathrm{Ks}=\{\mathrm{Ln}(\mathrm{LAA}+1,0)\} /$ $\{\mathrm{Ln}(\mathrm{CTA}+1,0)\}$;

$\left.8^{\circ}\right)$ LT = lâmina total de água no solo no final do dia ( $\left.=<\mathrm{CTA}\right)$, $\mathrm{mm}(\mathrm{LT}=\mathrm{LAA}-\mathrm{ETrc}+\mathrm{I}+\mathrm{P})$, sendo I = lâmina de irrigação aplicada, em mm, e $\mathrm{P}=$ precipitação pluviométrica, em mm;

$\left.9^{\circ}\right) \mathrm{Z}=$ profundidade efetiva do sistema radicular igual a $20 \mathrm{~cm}$ do plantio até 60 dias após, $30 \mathrm{~cm}$ de 60 até 120 dias após o plantio e $40 \mathrm{~cm}$ após este período.

Os nutrientes analisados foram: nitrogênio orgânico (Norg), nitrogênio nítrico $\left(\mathrm{NO}_{3}^{-}\right)$, fósforo $(\mathrm{P})$, potássio $(\mathrm{K})$, cálcio $(\mathrm{Ca})$, magnésio $(\mathrm{Mg})$, enxofre $(\mathrm{S})$, cloro $(\mathrm{Cl})$, sódio $(\mathrm{Na})$, ferro $(\mathrm{Fe})$, zinco $(\mathrm{Zn})$, cobre $(\mathrm{Cu})$, manganês $(\mathrm{Mn})$ e boro $(\mathrm{B})$. As análises foram realizadas de acordo com metodologias descritas por Malavolta et al. (1989) e Jones Jr. et al. (1991).

O Norg foi determinado pelo método de Nessler (Jackson, 1965), após submeter o material vegetal à oxidação pela digestão sulfúrica $\left(\mathrm{H}_{2} \mathrm{SO}_{4}\right.$ e $\left.\mathrm{H}_{2} \mathrm{O}_{2}\right)$. Para o $\mathrm{NO}_{3}$; utilizou-se o método de ultravioleta (Cawse, 1967), após submeter o tecido vegetal a banho-maria por 1 hora. O mesmo extrato submetido a banho-maria foi utilizado para a determinação do Cloreto, dosado por titulação com $\mathrm{AgNO}_{3}$. O P, determinado colorimetricamente pelo método do molibdato, e o $\mathrm{K}$, por espectrofotometria de emissão de chama, foram determinados no extrato obtido a partir da digestão sulfúrica. $\mathrm{O} \mathrm{Ca}, \mathrm{Mg}, \mathrm{Fe}$, $\mathrm{Zn}, \mathrm{Cu}, \mathrm{Na}$ e $\mathrm{Mn}$ foram quantificados, após oxidação do material vegetal pela digestão nitro-perclórica $\left(\mathrm{HNO}_{3}\right.$ e $\left.\mathrm{HClO}_{4}\right)$, por espectrofotometria de absorção atômica, com exceção do $\mathrm{Na}$, que foi determinado por espectrofotometria de emissão de chama. O S, utilizando também o extrato proveniente da digestão nitroperclórica, foi determinado por turbidimetria do sulfato. O B foi determinado, colorimetricamente, pela azometina $\mathrm{H}$, após incineração em mufla.

Foram realizadas análises de variância para os parâmetros quantificados, sendo que, para o fator época de amostragem de folhas, se compararam as médias pelo teste de Tukey, a 5\% de probabilidade, enquanto para os outros fatores utilizou-se análise de regressão polinomial, teste $\mathrm{F}$ da análise de variância da regressão e coeficientes do modelo estatisticamente significativos e maior $\mathrm{R}^{2}$.

\section{RESULTADOS E DISCUSSÃO}

Os teores foliares dos nutrientes apresentados nos Tabelas 1 e 2 correspondem, nas diversas épocas, ao tratamento em que Carvalho et al. (1999) verificaram a máxima produtividade de frutos no maracujazeiro-amarelo, ou seja, $531 \mathrm{~g} \mathrm{planta}^{-1}$ ano $^{-1}$ de K e lâmina de irrigação correspondente a $100 \%$ da ETo, ou lâmina total de água (precipitação efetiva + irrigação) igual a $1.476 \mathrm{~mm}$. Houve grande variação nos teores foliares da maioria dos nutrientes avaliados nas diversas épocas de coleta de folhas, não havendo diferenças, entre estas épocas, apenas para $\mathrm{NO}_{3}{ }^{-}$, 


\section{$\mathrm{Ca}$ e $\mathrm{Cu}$.}

Pode-se observar que os valores de N, P, K (Tabela 1) e Fe e $\mathrm{Zn}$ (Tabela 2) foram menores em nov./96, período que correspondeu ao pico de florescimento e início da colheita de fruto, sendo que, nesta época, os teores de $\mathrm{N}$ ficaram bem abaixo das faixas consideradas adequadas por Robinson (1986) e Malavolta et al. (1989). De modo geral, os teores foliares foram sempre menores nos períodos compreendidos entre o início do máximo florescimento (set./96) e quando ocorreram, em maior intensidade, florescimento e frutificação (nov./96). Resultados semelhantes foram observados por Menzel et al. (1993).

Os teores foliares de $\mathrm{P}, \mathrm{K}, \mathrm{Ca}$ e $\mathrm{Mn}$ estiveram, em todas as épocas, com exceção do P, em nov./96, abaixo da faixa considerada adequada por Malavolta et al. (1989), porém, dentro da faixa adequada apresentada por Robinson (1989). Os teores de $\mathrm{Zn}$ estiveram bem abaixo da faixa considerada adequada por Robinson (1986). É importante ressaltar que, independentemente de estarem ou não dentro de faixas consideradas adequadas por alguns pesquisadores, não foram verificados, no campo, sintomas de deficiências dos nutrientes.

Tanto para o Norg quanto para $\mathrm{O}_{3}^{-}$, foram verificados decréscimos lineares com o aumento das lâminas de irrigação (Figura 1), sendo que os mesmos, assim como para o $\mathrm{P}$ e o S, não foram afetados pelo incremento na adubação potássica. Quanto ao nitrato, Bar-Akiva et al. (1967; 1971; 1972 e 1974), citados por Kato (1986), encontraram que a concentração de $\mathrm{NO}_{3}^{-}$em folhas de citros e uva refletiam a taxa de aplicação de nitrogênio, e que existia uma relação positiva entre o conteúdo de nitrato, o nível de $\mathrm{N}$ foliar e a produtividade. Entretanto, a pouca variabilidade e os pequenos valores observados para o $\mathrm{NO}_{3}{ }^{-}$no limbo foliar do maracujazeiro-amarelo não permitiram que se fizessem estas inferências. Os mesmos autores sugerem que a atividade da redutase do nitrato pode ser usada como fator de avaliação do estado do nitrogênio foliar e da produtividade de uvas.

Com exceção das três primeiras épocas de amostragem foliar, os teores foliares de potássio aumentaram linearmente em função do adubo potássico aplicado (Tabela 3). Foram verificadas elevações que variaram entre 35\%, em nov./96, a 21\%, em maio/ 97 , nos teores foliares de $\mathrm{K}$, em função do aumento da dose de adubo potássico de 76 para $764 \mathrm{~g}_{\text {planta }}{ }^{-1} \mathrm{ano}^{-1}$ de $\mathrm{K}$.

$\mathrm{O}$ incremento de potássio no solo provocou uma redução linear nos teores foliares de $\mathrm{Mg}$, sendo que apenas em três épocas de amostragem não foram verificados efeitos. Verificaram-se decréscimos, entre a menor e a maior dose de $\mathrm{K}$ aplicada, de 14; 10; 20 e 16\% nos teores foliares do Mg em nov./ 96, jan./97, mar./97 e maio/97, respectivamente (Tabela 3). A redução dos teores de $\mathrm{Mg}$ nos tecidos foliares do maracujazeiroamarelo é atribuída ao efeito competitivo entre os íons $\mathrm{K}^{+}{\mathrm{e} \mathrm{Mg}^{++}}^{+}$ (Reis Jr., 1995; Malavolta et al., 1989; Rhue et al., 1986; Ologunde e Sorensen, 1982). Apenas em uma época, mar./97, observou-se a influência do adubo potássico sobre os teores foliares de $\mathrm{Ca}$ $\left(\mathrm{Y}=14,6-0,00323 \mathrm{~K}, \mathrm{R}^{2}=0,97 *\right)$.

É provável que a falta de resposta ao adubo potássico, nas três primeiras épocas de coleta de folhas (Tabela 3), se deva ao fato de este adubo ter sido aplicado na superfície do solo, numa faixa entre 30 e $40 \mathrm{~cm}$ de distância do colo da planta, e, possivelmente, o sistema radicular ainda pouco desenvolvido, não tivesse atingido esta faixa, estando, portanto, impossibilitado de absorver o $\mathrm{K}$ adicionado. Os teores de potássio, cálcio e magnésio na matéria seca foliar do maracujazeiro-amarelo não foram afetados pelas lâminas de irrigação.

Os resultados observados para o Mn (Tabela 2) estão bem abaixo daqueles verificados, em condições de campo, por Haag et. al. (1973) e por Menzel et al. (1993), fora da faixa considerada adequada por Malavolta et al. (1989) e no limite inferior da faixa apresentada por Robinson (1986). Porém, não foram observados sintomas tais como amarelecimento internerval e uma estreita faixa de tecido verde ao longo das nervuras, típicos de deficiência de Mn (Marschner, 1995). Segundo Marschner (1995), o nível crítico do manganês para a maioria das culturas varia entre 10 e $20 \mathrm{mg} \mathrm{kg}^{-1}$ de $\mathrm{Mn}$ na matéria seca de folhas maduras. As lâminas de irrigação não influenciaram os teores foliares do $\mathrm{Mn}$.

Os teores de $\mathrm{Mn}$ nas folhas decresceram com o aumento na dose do adubo potássico $\left(\mathrm{Y}=73,3-0,0152 \mathrm{~K}, \mathrm{R}^{2}=\right.$ $0,72 *)$. É possível que possa ter ocorrido competição entre os cátions $\mathrm{Mn}^{++}$e $\mathrm{K}^{+}$e, com isso, redução dos teores de manganês nos tecidos foliares. Além disso, é provável que haja perdas de $\mathrm{Mn}$, deslocado das partículas do solo pelo $\mathrm{K}$, por lixiviação, o que poderia causar, ao longo do tempo, deficiências deste micronutriente nas plantas.

O incremento de adubo potássico elevou, linearmente, os teores de $\mathrm{Cl}$ na matéria seca foliar do maracujazeiro-amarelo $\left(\mathrm{Y}=22,5+0,00292 \mathrm{~K}, \mathrm{R}^{2}=0,93 * *\right)$. Para a irrigação, observou-se um efeito quadrático nos teores de $\mathrm{Cl}$ na matéria seca foliar do maracujazeiro-amarelo, com aumento até a lâmina correspondente a $89,2 \%$ da ETo $\left(\mathrm{Y}=20,4+0,112 \mathrm{~K}-0,000628 \mathrm{~K}^{2}, \mathrm{R}^{2}=0,97 * *\right)$. Os acréscimos nos teores foliares de $\mathrm{Cl}$, em função da adubação potássica e das lâminas de irrigação, são devido à presença deste nutriente tanto no adubo utilizado, no caso o cloreto de potássio, quanto na água de irrigação.

$\mathrm{O}$ adubo potássico influenciou nos teores de zinco na matéria seca foliar do maracujazeiro-amarelo apenas na coleta de maio de $1997\left(\mathrm{Y}=34,6-0,0268 \mathrm{~K}+0,0000313 \mathrm{~K}^{2}, \mathrm{R}^{2}=0,77 * *\right)$. A utilização da irrigação não afetou os teores foliares do Zn, os quais estavam bem abaixo da faixa observada por Menzel et al. (1993) e daquela considerada adequada por Robinson (1986); porém, as médias observadas estão dentro da faixa considerada como adequada por Malavolta et al. (1989).

O boro, com média de $38 \mathrm{mg} \mathrm{kg}^{-1}$ de $\mathrm{B}$, o cobre, média de 24,2 $\mathrm{mg} \mathrm{kg}^{-1}$ de Cu, e o ferro, com média de $110 \mathrm{mg} \mathrm{kg}^{-1} \mathrm{de} \mathrm{Fe}$, não tiveram suas concentrações foliares influenciadas pela adubação potássica ou por lâminas de irrigação. Houve grande variação nos teores de $\mathrm{B}, \mathrm{Cu}$ e $\mathrm{Fe}$ entre as diversas épocas de coleta de folhas (Tabela 2). É interessante ressaltar que, para o Cobre, uma das possíveis causas desta variação deve-se a pulverizações, em algumas épocas, com fungicidas que continham, em sua formulação, altas concentrações deste elemento.

A adubação potássica decresceu linearmente os teores de sódio nas folhas do maracujazeiro-amarelo ( $\mathrm{Y}=2,27$ $\left.-0,00117 \mathrm{~K}, \mathrm{R}^{2}=0,93 * *\right)$. Verificou-se, entre a menor e a maior dose de K aplicada, uma redução de $70 \%$ nos teores de Na nas folhas. $\mathrm{O}$ efeito competitivo entre os íons $\mathrm{K}^{+} \mathrm{e} \mathrm{Na}^{+}$é a provável causa para o decréscimo nos teores de sódio nas folhas. Quanto à irrigação, verificou-se, entre a menor e a maior lâmina, um incremento de $32 \%$ nos teores de Na nas folhas do maracujazeiro- 


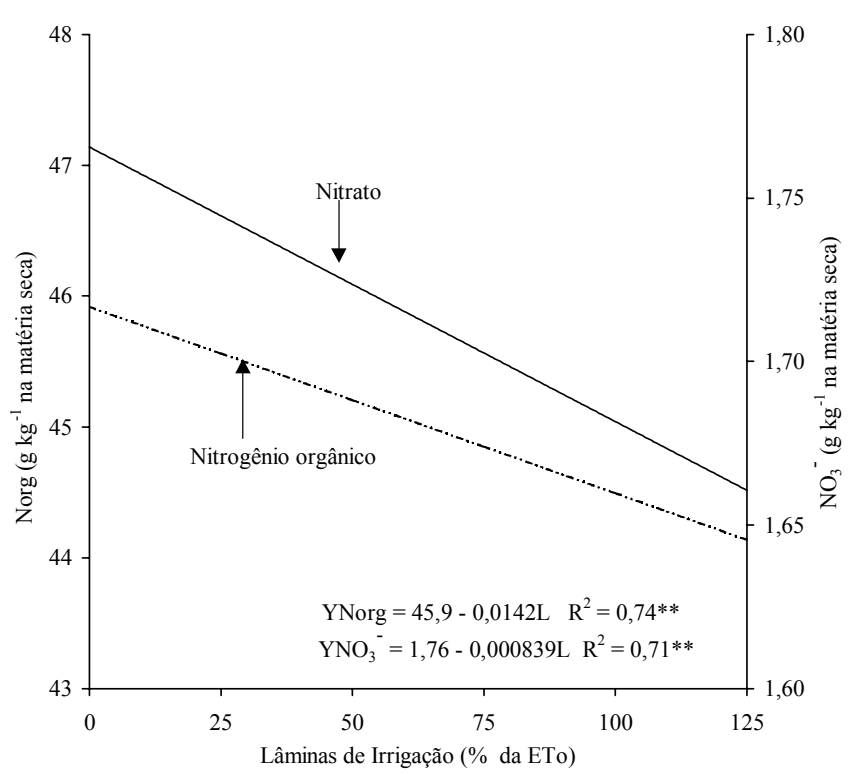

FIGURA 1 - Teores de Nitrogênio orgânico (Norg) e de Nitrato $\left(\mathrm{g} \mathrm{kg}^{-1}\right)$, na matéria seca foliar do maracujazeiroamarelo, em função das lâminas (L) de irrigação aplicada (em \% da ETo). amarelo $\left(\mathrm{Y}=1,57+0,0034 \mathrm{~L}, \mathrm{R}^{2}=0,70^{* *}\right)$. A presença do sódio na água utilizada para a irrigação é a mais provável explicação para este aumento nos teores deste elemento químico em função da irrigação. O teor médio de sódio encontrado na matéria seca foliar do maracujazeiro-amarelo foi de $1,46 \mathrm{~g} \mathrm{~kg}^{-1} \mathrm{de} \mathrm{Na}$, valores bem maiores que aqueles verificados, ao nível de campo, por Menzel et al. (1993).

\section{CONCLUSÕES}

1 - Os teores dos macronutrientes na matéria seca foliar, relacionados com a máxima produtividade de frutos, variaram entre as diferentes épocas do ano.

2 - Os teores de $\mathrm{Na}$ e de micronutrientes na matéria seca foliar, relacionados com a máxima produtividade de frutos, variaram entre as diferentes épocas.

3 - De modo geral, o adubo potássico elevou os teores de $\mathrm{K} \mathrm{e} \mathrm{Cl}$ e reduziu os de $\mathrm{Mg}, \mathrm{Mn}, \mathrm{Zn}$ e Na nas folhas do maracujazeiro. 4 - A irrigação afetou os teores de $\mathrm{N}$ orgânico, $\mathrm{NO}_{3}^{-}, \mathrm{Cl}$ e Na e não influenciou nos teores foliares dos demais nutrientes avaliados.

TABELA 1 - Teores de macronutrientes $\left(\mathrm{g} \mathrm{kg}^{-1}\right)$, na matéria seca foliar do maracujazeiro amarelo, em diferentes épocas, no tratamento onde se obteve a máxima produtividade de frutos

\begin{tabular}{lccccccc}
\hline \multirow{2}{*}{ ÉPOCA } & $\mathrm{Norg}$ & $\mathrm{NO}_{3}^{-}$ & $\mathrm{P}$ & $\mathrm{K}$ & $\mathrm{C} \mathrm{a}$ & $\mathrm{Mg}$ & $\mathrm{S}$ \\
\cline { 2 - 8 } & $\mathrm{g} \mathrm{kg} \mathrm{k}^{-1}$ & $\mathrm{~g} \mathrm{~kg}^{-1}$ & $\mathrm{~g} \mathrm{~kg}^{-1}$ & $\mathrm{~g} \mathrm{~kg}^{-1}$ & $\mathrm{~g} \mathrm{~kg}^{-1}$ & $\mathrm{~g} \mathrm{~kg}^{-1}$ & $\mathrm{~g} \mathrm{~kg}^{-1}$ \\
\hline abr./96 & $42,8 \mathrm{bcd}^{*}$ & $1,80 \mathrm{a}$ & $2,94 \mathrm{ab}$ & $23,5 \mathrm{c}$ & $15,1 \mathrm{a}$ & $2,94 \mathrm{abc}$ & $3,19 \mathrm{~b}$ \\
jun./96 & $47,0 \mathrm{abc}$ & $1,65 \mathrm{a}$ & $2,83 \mathrm{bc}$ & $26,3 \mathrm{bc}$ & $11,6 \mathrm{a}$ & $2,36 \mathrm{~cd}$ & $3,59 \mathrm{~b}$ \\
set./96 & $48,8 \mathrm{ab}$ & $1,74 \mathrm{a}$ & $3,05 \mathrm{ab}$ & $26,6 \mathrm{bc}$ & $10,6 \mathrm{a}$ & $2,13 \mathrm{~d}$ & $3,43 \mathrm{~b}$ \\
nov./96 & $34,7 \mathrm{a}$ & $1,51 \mathrm{a}$ & $2,31 \mathrm{c}$ & $24,1 \mathrm{c}$ & $13,8 \mathrm{a}$ & $2,55 \mathrm{bcd}$ & $3,73 \mathrm{ab}$ \\
jan./97 & $39,6 \mathrm{de}$ & $1,55 \mathrm{a}$ & $2,68 \mathrm{bc}$ & $29,2 \mathrm{abc}$ & $11,4 \mathrm{a}$ & $2,92 \mathrm{abc}$ & $3,10 \mathrm{~b}$ \\
mar./97 & $41,4 \mathrm{~cd}$ & $1,57 \mathrm{a}$ & $2,70 \mathrm{bc}$ & $31,7 \mathrm{ab}$ & $12,5 \mathrm{a}$ & $3,22 \mathrm{ab}$ & $3,57 \mathrm{~b}$ \\
maio/97 & $49,8 \mathrm{a}$ & $1,72 \mathrm{a}$ & $3,43 \mathrm{a}$ & $35,5 \mathrm{a}$ & $13,9 \mathrm{a}$ & $3,62 \mathrm{a}$ & $4,33 \mathrm{a}$ \\
\hline MÉDIA & 43,4 & 1,65 & 2,85 & 28,1 & 12,7 & 2,82 & 3,56 \\
\hline
\end{tabular}

*Em cada coluna, médias seguidas pela mesma letra não diferem significativamente, pelo teste de Tukey, a $5 \%$ de probabilidade.

TABELA 2 - Teores de Na e de micronutrientes, na matéria seca foliar do maracujazeiro-amarelo, em diferentes épocas, no tratamento onde se obteve a máxima produtividade de frutos

\begin{tabular}{|c|c|c|c|c|c|c|c|}
\hline ÉPOCA & $\mathrm{Na}$ & $\mathrm{C} 1$ & $\mathrm{Fe}$ & $\mathrm{Mn}$ & $\mathrm{Zn}$ & $\mathrm{Cu}$ & $\mathrm{B}$ \\
\hline jun./96 & $1,06 \mathrm{~b}$ & $22,1 \mathrm{ab}$ & $99 \mathrm{bc}$ & 75,6 ab & $29,2 \mathrm{ab}$ & 28,5 a & $24,7 \mathrm{~cd}$ \\
\hline nov./96 & $1,25 \mathrm{ab}$ & 25,1 a & $77 \mathrm{c}$ & $65,2 \mathrm{ab}$ & $26,1 \mathrm{~b}$ & 8,47 a & $39,5 \mathrm{abc}$ \\
\hline jan./97 & $1,24 \mathrm{ab}$ & $21,9 \mathrm{ab}$ & $125 \mathrm{ab}$ & $50,1 \mathrm{~b}$ & $29,3 \mathrm{ab}$ & 95,4 a & 54,5 a \\
\hline $\mathrm{m}$ ar. $/ 97$ & $1,41 \mathrm{ab}$ & $23,9 \mathrm{ab}$ & $102 \mathrm{bc}$ & $55,2 \mathrm{~b}$ & $31,8 \mathrm{ab}$ & $5,93 \mathrm{a}$ & $38,1 \mathrm{bcd}$ \\
\hline
\end{tabular}

*Em cada coluna, médias seguidas pela mesma letra não diferem significativamente, pelo teste de Tukey, a 5\% de probabilidade.

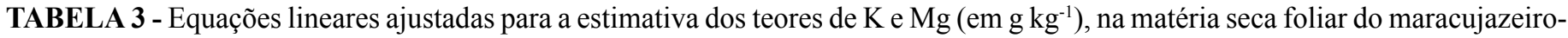
amarelo, em função de doses de $\mathrm{K}\left(\mathrm{g} \mathrm{planta}^{-1} \mathrm{ano}^{-1}\right)$ em diferentes épocas de coleta de folhas

\begin{tabular}{llcll}
\hline Época de coleta & \multicolumn{2}{c}{ Equações ajustadas para o $\mathrm{K}$} & \multicolumn{2}{c}{ Equações ajustadas para o Mg } \\
\hline abr./96 & $\mathrm{Y}=24,7$ & - & $\mathrm{Y}=2,86$ & - \\
jun./96 & $\mathrm{Y}=26,5$ & - & $\mathrm{Y}=2,35$ & - \\
set./96 & $\mathrm{Y}=26,5$ & $\mathrm{Y}=2,27$ & - \\
nov./96 & $\mathrm{Y}=19,1+0,0101 \mathrm{~K}$ & $\mathrm{R}^{2}=0,95^{* *}$ & $\mathrm{Y}=2,76-0,00058 \mathrm{~K}$ & $\mathrm{R}^{2}=0,98^{*}$ \\
jan./97 & $\mathrm{Y}=23,6+0,0112 \mathrm{~K}$ & $\mathrm{R}^{2}=0,84^{* *}$ & $\mathrm{Y}=3,10-0,00040 \mathrm{~K}$ & $\mathrm{R}^{2}=0,77^{\wedge}$ \\
mar./97 & $\mathrm{Y}=25,9+0,0128 \mathrm{~K}$ & $\mathrm{R}^{2}=0,94 * *$ & $\mathrm{Y}=3,42-0,00076 \mathrm{~K}$ & $\mathrm{R}^{2}=0,90^{* *}$ \\
maio/97 & $\mathrm{Y}=32,2+0,0109 \mathrm{~K}$ & $\mathrm{R}^{2}=0,96^{* *}$ & $\mathrm{Y}=4,10-0,00078 \mathrm{~K}$ & $\mathrm{R}^{2}=0,91 * *$ \\
\hline
\end{tabular}

$\wedge, * * \mathrm{e}^{*}$ significativo, respectivamente, a $10 ; 5$ e $1 \%$ de probabilidade, pelo teste de $\mathrm{F}$ 


\section{REFERÊNCIAS BIBLIOGRÁFICAS}

AGRIANUAL. 2000: Anuário da agricultura brasileira. Maracujá. São Paulo. FNP Consultoria e Comércio, 1999. p.391-406, 2000.

BERNARDO, S. Manual de Irrigação. Viçosa: Imprensa Universitária, 1995. 657p.

CARVALHO, A.J.C. de; MARTINS, D.P.; MONNERAT, P.H.; BERNARDO, S. Produtividade e qualidade do maracujazeiroamarelo em resposta à adubação potássica sob lâminas de irrigação. Revista Brasileira de Fruticultura, Jaboticabal-SP, SBF, v.21, n.3, p.333-337, dez./1999.

CAWSE, P.A. The determination of nitrate in soil solution by ultraviolet spectrophotometry. Analyst, v.9, n.2, p.309-313, 1967.

CLAASSEN, N.; WILCOX, G.E. Comparative reduction of calcium and magnesium composition of corn tissue by $\mathrm{NH}_{4}-\mathrm{N}$ and a K fertilization. Agronomy Journal, Madison, n.66, p.521$522,1974$.

DALIPARTHY, J.; BARKER, A.V.; MONDAL, S.S. Potassium fractions with other nutrients in crops: a review focusing on the tropics. Journal of Plant Nutrition, Monticello, v.17, n.11, p.18591886, 1994.

FONSECA, J.A. da; MEURER, E.J. Inibição da absorção de magnésio pelo potássio em plântulas de milho em solução nutritiva. Revista Brasileira de Ciência do Solo, Campinas, n.21, p.47-50, 1997.

HAAG, H.P.; OLIVEIRA, G.D.; BORDUCCHI, A.S.; SARRUGE, J.R. Absorção de nutrientes por duas variedades de maracujá. Anais da Escola Superior de Agricultura Luiz de Queiroz, Piracicaba, n.30, p.267-279, 1973.

JACKSON, M.L. Soil chemical analysis. New Jersey: Prentice Hall, 1965. 498p.

JONES JR., J.B.; WOLF, B.; MILLS, H.A. Plant Analysis Handbook: a practical sampling, preparation, analysis, and interpretation guide. Athens: Micro-Macro Publishing, 1991. 213p.

KATO, T. Nitrogen metabolism and utilization in citrus. Horticultural Reviews, New York, n.8, p.181-216, 1986.

KLIEMANN, H.J.; CAMPELO JR., J.H.; AZEVEDO, J.A. de, GUILHERME, M.R., GENÚ, P.J. de C. Nutrição mineral e adubação do maracujazeiro. In: HAAG, H.P., (Coord.) Nutrição mineral e adubação de frutíferas tropicais no Brasil. Campinas: Fundação Cargill, 1986. p.245-284.

LOCASCIO, S.J.; BARTZ, J.A.; WEIGARTNER, D.D. Calcium and potassium fertilization of potato grown in North Florida I. Effects on potato yield and tissue $\mathrm{Ca}$ and $\mathrm{K}$ concentration. American Potato Journal, Orono, v.69, n.2, p.95-104, 1992.

MALAVOLTA, E.; VITTI, G.C., OLIVEIRA, S.A. de. Avaliação do estado nutricional das plantas: princípios e aplicações. Piracicaba: POTAFOS, 1989. 201p.

MALAVOLTA, E. Nutricion y fertilizacion del maracuya. Quito: INPOFOS, 1994. 52p.

MARSCHNER, $\mathrm{H}$. Mineral nutrition of higher plants. London: Academic Press, 1995. 889p.

MENZEL, C.M.; HAYDON, G.E.; DOOGAN, V.J.; SIMPSON, D.R. New standard leaf nutrient concentrations for passionfruit based on seasonal phenology and leaf composition. Journal of Horticultural Science, Ashford, v.68, n.2, p.215-230, 1993.

OLOGUNDE, O.O., SORENSEN, R.C. Influence of K and Mg in nutrient solutions on sorghum. Agronomy Journal, Madison, v.74, n.1, p.41-46, 1982.

RAIJ, B. van. Fertilidade do solo e adubação. Piracicaba: Ceres/ POTAFOS, 1991.343p.

REIS Jr., R. dos A. Produção, qualidade de tubérculos e teores de potássio no solo e no pecíolo de batateira em resposta à adubação potássica. 1995. 108f. Dissertação (Mestrado em Fitotecnia) - Universidade Federal de Viçosa, Viçosa, 1995.

RHUE, R.D.; HENSEL, D.R.; KIDDER, G. Effect of K fertilization on yield and leaf nutrient concentrations of potatoes grown on a sandy soil. American Potato Journal, Orono, n. 63, p.665-81, 1986.

ROBINSON, J.B. Fruits, Vines eNuts. REUTER, D.J.; ROBINSON, J.B. (Ed.) Plant analysis: an interpretation manual. Melbourne: Inkata Press, 1986. p.120-147.

SHIKHAMANY, S.D.; IYER, C.P.A.; HARIPRAKASA RAO, M.; SUBRAMANIAN, T.R. Variation in the seasonal nutrient status in relation to different yield patterns in guava cv. Allahabad Safeda. Indian Journal of Horticulture, Bangalore, v.43, n.1-2, p.73-78, 1986. 